\title{
SSR and AFLP based genetic diversity of soybean germplasm differing in photoperiod sensitivity
}

\author{
Ram K. Singh ${ }^{1,3^{*}}$, Virendra S. Bhatia ${ }^{1}$, K.V. Bhat ${ }^{2}$, Trilochan Mohapatra ${ }^{3}$, Nagendra K. Singh ${ }^{3}$, \\ Kailash C. Bansal ${ }^{3}$ and K.R. Koundal ${ }^{3}$ \\ ${ }^{1}$ National Research Centre for Soybean, Indore, India. \\ ${ }^{2}$ National Research Centre for DNA Fingerprinting, National Bureau of Plant Genetic Resources, \\ Pusa Campus, New Delhi, India. \\ ${ }^{3}$ National Research Centre on Plant Biotechnology, Indian Agricultural Research Institute, Pusa Campus, \\ New Delhi, India.
}

\begin{abstract}
Forty-four soybean genotypes with different photoperiod response were selected after screening of 1000 soybean accessions under artificial condition and were profiled using 40 SSR and 5 AFLP primer pairs. The average polymorphism information content (PIC) for SSR and AFLP marker systems was 0.507 and 0.120 , respectively. Clustering of genotypes was done using UPGMA method for SSR and AFLP and correlation was 0.337 and 0.504 , respectively. Mantel's correlation coefficients between Jaccard's similarity coefficient and the cophenetic values were fairly high in both the marker systems (SSR $=0.924$; AFLP $=0.958$ ) indicating very good fit for the clustering pattern. UPGMA based cluster analysis classified soybean genotypes into four major groups with fairly moderate bootstrap support. These major clusters corresponded with the photoperiod response and place of origin. The results indicate that the photoperiod insensitive genotypes, 11/2/1939 (EC 325097) and MACS 330 would be better choice for broadening the genetic base of soybean for this trait.
\end{abstract}

Key words: photoperiod response, SSR, AFLP, genetic diversity, soybean.

Received: April 28, 2009; Accepted: December 1, 2009.

The photoperiod response is a major criterion, which determines the latitudinal adaptation of a soybean variety (Hartwig and Kiihl, 1979). A considerable variation in the relative sensitivity of soybean genotypes to differences in photoperiod has been reported (Sinclair and Hinson, 1992). Roberts et al. (1996) had also emphasized the importance of photoperiod-insensitivity in the improvement of soybean crop after characterizing soybean genotypes in conjunction with an analysis of the world-wide range of photo-thermal environments in which soybean crops are grown. Most of the Indian soybean cultivars $(>95 \%)$ were found to be highly sensitive to photoperiod that limits their cultivation in only localized area (Bhatia et al., 2003). Thus, it is important to identify genetically diverse source of photoperiod-insensitivity gene(s) to broaden the genetic base of Indian soybean cultivars.

Better knowledge of the genetic similarity of breeding materials could help to maintain genetic diversity and

Send correspondence to Ram K. Singh. Division of Crop Improvement, Indian Institute of Sugarcane Research, Rai Bareli Road, Lucknow-226002 U.P., India. E-mail: ikrps@yahoo.com.

"Present address: Division of Crop Improvement, Indian Institute of Sugarcane Research, Lucknow-226002 India. sustain long-term selection gains. Furthermore, monitoring the genetic variability within the gene pool of elite breeding material could make crop improvement more efficient by the directed accumulation of favored alleles thus decreasing the amount of material to be screened. Several studies have used molecular markers to help in identification of genetically diverse genotypes to use in crosses in cultivar improvement programme. These studies have more success than conventional selection programme in producing productive lines from plant introduction/exotic lines crosses with elite lines (Maughan et al., 1996; Thompson and Nelson, 1998). Among the molecular markers simple sequence repeats (SSR) are reproducible, co-dominant and distributed through out the genome. The AFLPs being dominant markers allow studying many loci simultaneously and generating highly reproducible markers that are also considered to be locus specific within a species (Maughan et al., 1996). These two markers can detect higher levels of genetic diversity in soybean and have been utilized for many purposes including genome mapping, gene tagging, estimation of genetic diversity and varietal identification (Maughan et al., 1995, 1996; Powell et al., 1996; Cregan et al., 1999; Brown-Guedira et al., 2000; Narvel et al., 2000; 
Ude et al., 2003; Wange et al., 2006; Singh et al., 2008). However, no information is available on assessment of genetic diversity in response to photoperiodism in soybean. The present study was conducted to identify genetic diversity in the soybean gene pool for photoperiod insensitivity using SSR and AFLP markers.

One thousand soybean genotypes obtained from India, USA, Hungary, Philippines and Taiwan were screened for sensitivity to photoperiodism as described by Singh et al. (2008). Out of these 44 genotypes, 15 genotypes showing different degree of photoperiod insensitivity and 29 sensitive genotypes were selected for analysis using SSR and AFLP markers. The place of origin, EC number and their response to photoperiodism are given in Table 1. Ten leaves, one each from ten plants of 44 soybean genotypes were collected and DNA was isolated by the method described by Doyle and Doyle (1990).

Simple sequence repeat (SSR)/ microsatellite analysis was carried out using 40 mapped markers distributed on all the 20 chromosomes (Cregan et al., 1999) (Table 2). Amplification was carried out in a $10 \mu \mathrm{L}$ reaction mixture consisting of $1 \mathrm{X}$ PCR assay buffer (Bangalore Genei Pvt. Ltd., India), $200 \mu \mathrm{M}$ of the four dNTPs (MBI Fermentas, Lithuania, USA), $12 \mathrm{ng}$ (1.8 picomole) each of forward and reverse primers (Life Technologies, USA), 0.5 units of Taq DNA polymerase (Bangalore Genei Pvt. Ltd., India) and $25 \mathrm{ng}$ template DNA. PCR reactions were carried out in a thermal cycler (Gene Amp 9600 model, version 2.01 from Perkin Elmer, USA) using the following cycling parameters: initial denaturation at $94^{\circ} \mathrm{C}$ for $5 \mathrm{~min}$, followed by 35 cycles of $94{ }^{\circ} \mathrm{C}$ for $1 \mathrm{~min}, 55^{\circ} \mathrm{C}$ for $1 \mathrm{~min}, 72{ }^{\circ} \mathrm{C}$ for $2 \mathrm{~min}$ and finally a primer extension cycle of $7 \mathrm{~min}$ at $72{ }^{\circ} \mathrm{C}$. The amplification products were separated on $3 \%$ metaphor agarose gels containing $1.5 \%$ gel star (FMC Bio Products, Rockland, USA). Gels were run for $3 \mathrm{~h}$ at $50 \mathrm{~V}$ in $1 \mathrm{X}$ TBE buffer. DNA fragments were visualized under UV light and photographed using a Polaroid photographic system. The size of the fragments was estimated using a 50-bp DNA ladder (MBI Fermentas, Lithuania).

AFLP fingerprints were generated based on the protocol of Zabeau and Vos (1993) with the AFLP Analysis System II (Invitrogen Corporation, Grand Island, NY) following the manufacturer's instructions. The size of the fragments was estimated using a 20-bp DNA ladder (MBI Fermentas, Lithuania).

The scoring of bands was done as present (1) or absent (0) for each AFLP and SSR marker allele and data was entered in a binary data matrix as discrete variables. Jaccard's coefficient of similarity was calculated and a dendrogram was constructed by using Unweighted Pair Group Method of Arithmetic Mean (UPGMA). The computer package NTSYS-PC Version 2.02 (Rohlf, 1998) was used for cluster analysis. The same software was used to perform the Mantel test of correlation between the cophenetic values and the Jaccard similarity coefficients to ascer-
Table 1 - Genotypes and cultivars, country of origin and classification regarding sensitivity to photoperiodism of the 44 soybean genotypes/cultivars used in this study.

\begin{tabular}{|c|c|c|c|c|}
\hline S. no. & $\begin{array}{l}\text { Collection } \\
\text { Id. }\end{array}$ & $\begin{array}{l}\text { Variety or origi- } \\
\text { nal identity }\end{array}$ & $\begin{array}{l}\text { Country of } \\
\text { origin of } \\
\text { germplasm } \\
\text { collection }\end{array}$ & $\begin{array}{l}\text { Classifica- } \\
\text { tion* }\end{array}$ \\
\hline 1 & MACS 330 & Cultivar & India & I \\
\hline 2 & EC 325097 & $11 / 2 / 1939$ & Hungary & I \\
\hline 3 & EC 333897 & Maple Arrow & USA & I \\
\hline 4 & EC 34101 & Dun-NunII-2-15 & Hungary & I \\
\hline 5 & EC 325118 & $1158 / 84$ & Hungary & I \\
\hline 6 & EC 325100 & $1145 / 84$ & Hungary & LS \\
\hline 7 & LSb 1 & Cultivar & India & LS \\
\hline 8 & EC 333922 & PI 437418 & USA & LS \\
\hline 9 & EC 325106 & $1146 / 84$ & Hungary & MS \\
\hline 10 & EC 251402 & S-100 & China & MS \\
\hline 11 & EC 333912 & PI 424-489A & USA & MS \\
\hline 12 & EC 325114 & $2426 / 85$ & Hungary & MS \\
\hline 13 & EC 333920 & LAKOTA & USA & MS \\
\hline 14 & EC 232075 & ROMEA & Philippines & MS \\
\hline 15 & EC 333880 & Evans & USA & MS \\
\hline 16 & EC 325159 & $111-3-250$ & Hungry & HS \\
\hline 17 & EC 325115 & $1172 / 84$ & Hungary & HS \\
\hline 18 & EC 333925 & PI 437428A & USA & HS \\
\hline 19 & EC 325117 & $1165 / 84$ & Hungary & HS \\
\hline 20 & EC 333867 & Harosoy & USA & HS \\
\hline 21 & EC 333919 & Hedgson & USA & HS \\
\hline 22 & AGS 16 & - & Taiwan & HS \\
\hline 23 & EC 175321 & G-1594 & Taiwan & HS \\
\hline 24 & EC 242091 & 30229-11-11 & Philippines & HS \\
\hline 25 & EC 358004 & PI 437833 & USA & HS \\
\hline 26 & EC 251770 & Pershing & USA & HS \\
\hline 27 & Samarat & Cultivar & India & HS \\
\hline 28 & EC 103336 & CES-434 & Philippines & HS \\
\hline 29 & EC 291448 & PI 90-763 & USA & HS \\
\hline 30 & EC 378783 & - & USA & HS \\
\hline 31 & EC 333904 & PI 404-177 & USA & HS \\
\hline 32 & EC 251446 & Jackson & USA & HS \\
\hline 33 & Type 49 & Cultivar & India & HS \\
\hline 34 & Hardee & Cultivar & India & HS \\
\hline 35 & Co1 & Cultivar & India & HS \\
\hline 36 & JS80-21 & Cultivar & India & HS \\
\hline 37 & GS1 & Cultivar & India & HS \\
\hline 38 & NRC 37 & Cultivar & India & HS \\
\hline 39 & PK 472 & Cultivar & India & HS \\
\hline 40 & MAUS 32 & Cultivar & India & HS \\
\hline 41 & Indirasoya-9 & Cultivar & India & HS \\
\hline 42 & MACS 58 & Cultivar & India & HS \\
\hline 43 & MACS124 & Cultivar & India & HS \\
\hline 44 & MACS13 & Cultivar & India & HS \\
\hline
\end{tabular}

*I = Photoperiod insensitive; $\mathrm{LS}=$ Low sensitivity; $\mathrm{MS}=$ moderate sensitivity; $\mathrm{HS}=$ high sensitivity. 
Table 2 - SSR loci, linkage group with position, allele number and polymorphism information content (PIC) for 44 soybean genotypes/cultivars.

\begin{tabular}{|c|c|c|c|c|c|}
\hline $\begin{array}{l}\text { SSR } \\
\text { primer pair }\end{array}$ & $\begin{array}{c}\text { Primer } \\
\text { name }\end{array}$ & $\begin{array}{l}\text { Linkage } \\
\text { group }\end{array}$ & $\begin{array}{c}\mathrm{cM} \\
\text { position }\end{array}$ & $\begin{array}{l}\text { No. of } \\
\text { alleles }\end{array}$ & PIC \\
\hline 1 & Satt276 & $\mathrm{A} 1$ & 5.70 & 3 & 0.613 \\
\hline 2 & Satt211 & A1 & 95.96 & 3 & 0.369 \\
\hline 3 & Satt493 & $\mathrm{A} 2$ & 35.02 & 1 & 0 \\
\hline 4 & Satt233 & $\mathrm{A} 2$ & 100.09 & 3 & 0.520 \\
\hline 5 & Satt415 & $\mathrm{B} 1$ & 0.8 & 5 & 0.616 \\
\hline 6 & Satt063 & B 2 & 93.49 & 4 & 0.584 \\
\hline 7 & Satt126 & B2 & 27.63 & 3 & 0.644 \\
\hline 8 & Satt194 & $\mathrm{C} 1$ & 26.35 & 2 & 0.118 \\
\hline 9 & Satt524 & $\mathrm{C} 1$ & 120.12 & 1 & 0 \\
\hline 10 & Satt170 & $\mathrm{C} 2$ & 70.56 & 2 & 0.080 \\
\hline 11 & Satt460 & $\mathrm{C} 2$ & 117.77 & 4 & 0.575 \\
\hline 12 & Satt184 & Dla & 17.52 & 3 & 0.581 \\
\hline 13 & Satt129 & Dla & 109.67 & 2 & 0.384 \\
\hline 14 & Satt216 & D1b & 9.80 & 4 & 0.728 \\
\hline 15 & Satt459 & D1b & 118.6 & 3 & 0.224 \\
\hline 16 & Satt498 & D2 & 32.14 & 2 & 0.118 \\
\hline 17 & Sat_114 & $\mathrm{D} 2$ & 84.18 & 2 & 0.249 \\
\hline 18 & Satt231 & E & 70.23 & 3 & 0.503 \\
\hline 19 & Satt411 & E & 12.92 & 6 & 0.703 \\
\hline 20 & SOYHSP176 & F & 68.44 & 4 & 0.718 \\
\hline 21 & Satt072 & F & 87.01 & 1 & 0 \\
\hline 22 & Satt038 & G & 1.84 & 5 & 0.772 \\
\hline 23 & Sct_ 187 & G & 107.11 & 3 & 0.249 \\
\hline 24 & Sat_127 & $\mathrm{H}$ & 28.80 & 4 & 0.653 \\
\hline 25 & Satt434 & $\mathrm{H}$ & 105.74 & 4 & 0.663 \\
\hline 26 & Satt587 & I & 31.49 & 1 & 0 \\
\hline 27 & Satt354 & I & 46.22 & 6 & 0.796 \\
\hline 28 & Satt431 & $\mathrm{J}$ & 78.57 & 4 & 0.684 \\
\hline 29 & Sct_046 & $\mathrm{J}$ & 24.09 & 1 & 0 \\
\hline 30 & Satt539 & $\mathrm{K}$ & 1.80 & 2 & 0.041 \\
\hline 31 & SOYPRP1 & $\mathrm{K}$ & 46.94 & 5 & 0.752 \\
\hline 32 & Satt388 & $\mathrm{L}$ & 23.55 & 1 & 0 \\
\hline 33 & Satt278 & $\mathrm{L}$ & 31.22 & 4 & 0.639 \\
\hline 34 & Sat_099 & $\mathrm{L}$ & 78.23 & 4 & 0.609 \\
\hline 35 & GMSC514 & M & 3.05 & 3 & 0.292 \\
\hline 36 & Satt346 & M & 112.79 & 3 & 0.642 \\
\hline 37 & Sat_084 & $\mathrm{N}$ & 36.86 & 2 & 0.353 \\
\hline 38 & GMABAB & $\mathrm{N}$ & 73.10 & 4 & 0.749 \\
\hline 39 & Sat_132 & $\mathrm{O}$ & 8.75 & 4 & 0.352 \\
\hline 40 & Sat_109 & $\mathrm{O}$ & 127.50 & 5 & 0.674 \\
\hline
\end{tabular}

tain reliability of the obtained clusters. Robustness of the clustering pattern was also tested using bootstrap analysis using Free Tree - Free ware software (Pavlicek et al., 1999). The polymorphism information content (PIC) was calculated for SSR marker as $1-\Sigma p_{i j}{ }^{2}$ where $p_{i j}$ is the frequency of the $j^{\text {th }}$ allele of $i^{\text {th }}$ marker (Weir, 1990) while PIC for
AFLP marker was calculated as described by Powell et al. (1996).

Among the 40 SSR primer pairs used in the present study, $34(85.0 \%)$ were polymorphic, while six primers revealed monomorphic patterns. In total, 120 alleles were detected for the 34 polymorphic SSR primers, with an average of 3.53 alleles per locus. Allele sizes ranged from $90 \mathrm{bp}$ to $300 \mathrm{bp}$. Summarized data for the SSR loci and their PIC values are presented in Table 2. The PIC value, a reflection of allelic diversity and frequency among the soybean genotypes analyzed were generally high for all the SSR loci tested. PIC values ranged from 0.041 to 0.796 , with an average of 0.507 . Seven SSR loci revealed PIC values higher than 0.70. Among these, Satt354 and Satt038 are noteworthy due to their relatively high polymorphism (six and five alleles each, respectively), and high PIC values (0.796 and 0.772), respectively. The polymorphism of SSR loci detected in this study was consistent with data obtained in some previous studies (Doldi et al., 1997; Brown-Guedira et al., 2000; Narvel et al., 2000), but was lower than that reported by others (Rongwen et al., 1995; Diwan and Cregan, 1997). The PIC values of our study were in agreement with the data of Doldi et al. (1997) and Brown-Guedira et al. (2000), who detected mean gene diversity values of 0.50 and 0.69 in a group of 39 and 36 elite/commercial soybean cultivars, respectively.

The five AFLP primer combinations used in this study were selected on the basis of a high number of scorable polymorphic bands. It was possible to discriminate each one of the 44 soybean genotypes using five primer combinations. Band sizes ranged from 100 to $700 \mathrm{bp}$. The five primer pairs revealed a total of 449 different bands that were of sufficient intensity to be scored, and $208(46.3 \%)$ of these were polymorphic. The percentage of polymorphic bands per assay unit ranged from $34.0 \%$ (EACT/M-CAT) to $57 \%$ (E-AAG/M-CTT), with an average of $46.3 \%$. The average PIC score for AFLP primer combination was 0.12 , with a range of 0.08 to 0.16 (Table 3 ). A similar average PIC score for AFLP was also reported in an earlier study on soybean (Ude et al., 2003). 91 polymorphic bands showed PIC scores $>0.30$ indicating that only $20.3 \%$ of the 449 bands contributed significantly to the genetic variation of the soybean genotypes. A PIC score $>0.30$ has been described previously in soybean based on RFLP (Keim et al., 1992; Lorenzen et al., 1995), RAPD (Thompson and Nelson, 1998) and AFLP (Ude et al., 2003) results and shows its usefulness in other soybean germplasm diversity studies. Thus, the polymorphism seen by SSR and AFLP efficiently distinguished all these accessions of soybean genotypes.

The similarity coefficients based on shared SSR and AFLP bands revealed that the average genetic similarity (GS) between genotypes was 0.446 , with a range of 0.220 to 0.765 . GS estimates for AFLP and SSR were 0.504 and 0.337 , respectively. As expected, the level of polymor- 
Table 3 - Total number of bands, proportion of polymorphic bands and polymorphism information content (PIC) for each AFLP primer pair used in the analysis of 44 soybean lines.

\begin{tabular}{lccc}
\hline Primer pair & $\begin{array}{c}\text { Total no. of } \\
\text { bands }\end{array}$ & $\begin{array}{c}\text { Proportion of poly- } \\
\text { morphic bands }\end{array}$ & PIC \\
\hline E-ACC/M-CAA & 89 & 0.55 & 0.15 \\
E-AAG/M-CTT & 101 & 0.57 & 0.16 \\
E-ACC/M-CAC & 75 & 0.47 & 0.12 \\
E-ACA/M-CAC & 86 & 0.43 & 0.08 \\
E-ACT/M-CAT & 98 & 0.34 & 0.097 \\
\hline
\end{tabular}

phism was higher for SSR (0.507) than for AFLP (0.12), reflecting the hypervariability of SSR markers. SSR/microsatellite analysis thus revealed significantly lower mean genetic similarity values (0.337) than AFLP (0.504). Similar results have been reported for soybean (Powell et al., 1996) and olive (Bandelj et al., 2003). Dendrograms were constructed from genetic similarity data, and clusters were tested for associations. Cophenetic coefficients were fairly high in both molecular systems $(\mathrm{SSR}=0.924$ and AFLP $=0.958$ ) indicating a good fit for clustering. The Mantel correlation test was used to compare between SSR and AFLP, as well as the combined data. The cophenetic matrix values and the estimated correlations for the two molecular systems and with combination were $r=0.604$ (SSR vs. AFLP), $\mathrm{r}=0.771$ (SSR vs. combination) and 0.971 (AFLP vs. combination), respectively. All these were statistically significant. The slightly lower level of correlation between SSR and AFLP in the present study could probably reflect that these markers are known to target different genomic fractions involving repeat and/or unique sequences, which may have differentially evolved or been preserved during the course of natural or artificial selection.

Cluster analysis based on coefficient of similarity classified the soybean genotypes into four major clusters, which were designated as I, II, III and IV in this study (Figure 1). The dendrogram indicated that $82 \%$ of the 44 soybean genotypes clustered in the range of 0.55 to 0.76 similarity coefficients. A correspondence between photoperiodism and place of origin of the cultivars was evident from Figure 1. The Mantel test indicated good fit for the clustering pattern with fairly moderate bootstrap supports (65\%-100\%). The cluster 'I' was composed of six genotypes from USA, five from Hungary, three from Philippines, two from Taiwan and one from China, however S-100 appeared as an outlier in this group (Figure 1). Flowering in this group was delayed from 12-68 days in extended photoperiod. Grouping of soybean ancestors/cultivars ftom the USA with Hungarian, French and Japanese genotypes was also reported (Brown-Guedira et al., 2000). The grouping of Jackson, S-100, Evans and Pershing in different subclusters in the present study is in the agreement with previous results (Ude et al., 2003). Cluster II mainly consisted of Indian soybean cultivars (14 cultivars) along

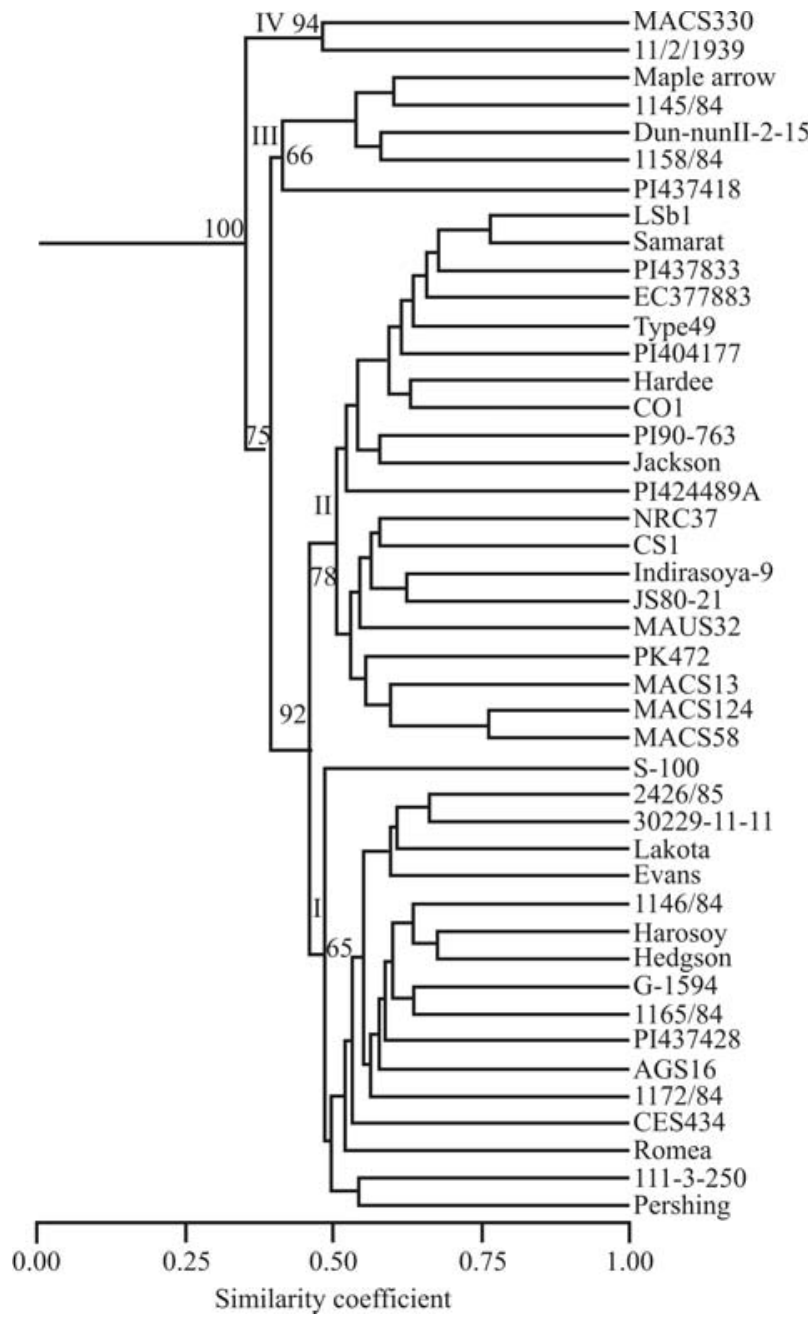

Figure 1 - Dendrogram of 44 soybean lines produced by the UPGMA clustering method based on a genetic similarity matrix derived from 120 SSR and 449 AFLP markers. Bootstrap values in percentages for the four major clusters are mentioned at the respective nodes. The major clusters are indicated as I, II, III and IV node on the left side.

with six genotypes from the USA and was again divided into subclusters. The genotypes of this group did not flower under extended photoperiods and are highly photoperiodsensitive, except for LSb1 and PI424-489A, which flowered after 7 and 14 days under extended photoperiod, respectively. Grouping of six genotypes/cultivars from the USA along with Indian soybean cultivars in II-a is obvious, as most of the initial Indian soybean varieties are either direct introductions from theUSA or were selected or bred using introductions as one of the parent (Karmakar and Bhatnagar, 1996). The genotypes of subgroup II - b comprised only Indian soybean cultivars and clustered together with $53 \%$ similarity. The Indian soybean cultivars shown to cluster in this study mainly came from the central and southern zones of India, and the result is in agreement with an earlier report (Hymowitz and Kaizuma, 1981).

Cluster III consisted of four genotypes (three from Hungary (1145/84, Dun NunII-2-15, 1158/84) and one 
from the USA (Maple Arrow), which grouped together with 0.545 similarities. Though genotype PI 437418 did not group with cluster III, it showed a reasonable level of similarity with this cluster and, thus can be considered as an outlier of this group. The genotypes of this group showed delayed flowering from 1-5 days in extended photoperiod. Cluster IV included one genotype each from Hungary and India. This cluster consisted of diverse genotypes (MACS330, a cross from Monetta (USA) X EC95937 (USSR), and 11/2/1939, a line from Hungary) which showed no delay in flowering under extended photoperiod. The cluster formed by these two genotypes is not strong and showed only 0.50 similarity between each of its members, which, in turn, showed 0.36 similarity with other genotypes of the present study. It is evident from dendrogram (Figure 1) that soybean cultivars/genotypes from the USA grouped along with genotypes of different origin in different clusters, the reason being that a large number of the accessions in the USDA soybean collection are from the same regions of China and Korea. These introductions that make up the base of the American germplasm (Brown-Guedira et $a l ., 2000)$ were used for development of soybean cultivars in the USA.

Soybean producing regions in India range from the lower Himalayan Hills and Northern Plain in the north to the Deccan Plateau in the south. The soybean varieties cultivated in these areas were developed through separate breeding programs, because most of the Indian soybean varieties are photoperiod sensitive, restricting their cultivation to localized areas only. The genotypes, 11/2/1939 (Hungary) and MACS330 (India) identified as photoperiod insensitive in the present study formed a separate group, as clearly shown by UPGMA (Figure 1). Literature reports indicate that there is a relationship between marker diversity of parents and genetic variance of the resulting progeny. Collecting data on genetic diversity in parents and progeny, however, is time consuming and expensive (Maughan et al., 1996). Thus, identifying genetically diverse parents based for desirable trait based on molecular markers would be a good approach for the production of desirable progeny. This approach has been already used for production of high yielding progeny in soybean (Thompson and Nelson, 1998). In the present study, we are making available potential germplasm resources for photoperiod insensitivity to soybean breeders that can be used for introgression of photoperiod insensitivity genes into soybean cultivars for wider adaptability.

\section{Acknowledgments}

R.K. Singh is grateful to the National Agricultural Technology Project (Team of Excellence), Indian Council of Agricultural Research, Government of India for the fellowship. The authors thank the Director of NRC for Soybean Indore for facilities and support provided.

\section{References}

Bandelj D, Jakse J and Javornik B (2003) Assessment of genetic variability of olive varieties by microsatellite and AFLP markers. Euphytica 136:93-102.

Bhatia VS, Yadav S, Rashmi A, Lakshami N and Guruprasad KN (2003) Assessment of photoperiod sensitivity for flowering in Indian soybean varieties. Ind J Plant Physiol 8:81-84.

Brown-Guedira GL, Thompson JA, Nelson RL and Warburton ML (2000) Evaluation of genetic diversity of soybean introductions and North American ancestors using RAPD and SSR markers. Crop Sci 40:815-823.

Cregan PB, Jarvik T, Bush AL, Shoemaker RC, Lark KG, Kahler AL, Kaya N, VanToai TT, Lohnes DG, Chung J et al. (1999) An integrated genetic linkage map of the soybean. Crop Sci 39:1464-1490.

Diwan N and Cregan PB (1997) Automated sizing of fluorescent-labeled simple sequence repeat (SSR) markers to assay genetic variation in soybean. Theor Appl Genet 95:723-733.

Doldi ML, Vollmann J and Lelley T (1997) Genetic diversity in soybean as determined by RAPD and microsatellite analysis. Plant Breed 116:331-335.

Doyle JJ and Doyle JL (1990) Isolation of plant DNA from fresh tissue. Focus 12:13-14.

Hartwig EE and Kiihl RAS (1979) Identification and utilization of a delayed flowering character in soybeans for short day conditions. Field Crop Res 2:145-151.

Hymowitz T and Kaizuma N (1981) Soybean seed protein electrophoresis profiles from 15 Asian countries or regions: Hypotheses on paths of dissemination of soybeans from China. Econ Bot 35:10-23.

Karmakar PG and Bhatnagar PS (1996) Genetic improvement of soybean varieties released in India from 1969 to 1993. Euphytica 90:95-103.

Keim P, Beavis W, Schupp J and Freestone R (1992) Evaluation of soybean RFLP marker diversity in adapted germplasm. Theor Appl Genet 85:205-212.

Lorenzen LL, Boutin S, Young N, Specht JE and Shoemaker RC (1995) Soybean pedigree analysis using map- based markers: I. Tracking RFLP markers in cultivars. Crop Sci 35:1326-1336.

Maughan PJ, Saghai Maroof MA and Buss GR (1995) Microsatellite and amplified sequence length polymorphism in cultivated and wild soybean. Genome 38:715-725.

Maughan PJ, Saghai Maroof MA, Buss GR and Huestis GM (1996) Amplified fragment length polymorphism (AFLP) in soybean: Species diversity, inheritance and near isogenic line analysis. Theor Appl Genet 93:392-401.

Narvel JM, Fehr WR, Chu W, Grant D and Shoemaker RC (2000) Simple sequence repeats diversity among soybean plant introduction and elite genotypes. Crop Sci 40:1452-1458.

Pavlicek A, Hrda S and Flegr J (1999) Free Tree - Freeware program for construction of phylogenetic trees on the basis of distance data and bootstrap/jackknife analysis of the tree robustness. Application in the RAPD analysis of the genus Frenkelia. Folia Biol 45:97-99.

Powell W, Morgante M, Andre C, Hanafey M, Vogel J, Tingey S and Rafalski A (1996) The comparison of RFLP, RAPD, AFLP and SSR (microsatellite) markers for germplasm analysis. Mol Breed 2:225-238.

Roberts EH, Qi A, Ellis RH, Summerfield RJ, Lawn RJ and Shanmugasundaram S (1996) Use of field observations to 
characterize genotypic flowering responses to photoperiod and temperature: A soybean exemplar. Theor Appl Genet 93:519-533.

Rohlf FJ (1998) NTSYS-PC Numerical Taxonomy and Multivariate Analysis system. Exeter Software, New York.

Rongwen J, Akkaya MS, Lavi U and Cregan PB (1995) The use of microsatellite DNA markers for soybean genotype identification. Theor Appl Genet 19:43-48.

Sinclair TR and Hinson K (1992) Soybean flowering in response to the long juvenile trait. Crop Sci 32:1242-1248.

Singh RK, Bhat KV, Bhatia VS, Mohapatra T and Singh NK (2008) Association mapping for photoperiod insensitivity trait in soybean. Natl Acad Sci Lett 31:281-283.

Thompson JA and Nelson RL (1998) Utilization of diverse germplasm for soybean yield improvement. Crop Sci 38:1362-1368.

Ude GN, Kenworthy WJ, Costa JM, Cregan PB and Alvernaz J (2003) Genetic diversity of soybean cultivars from China,
Japan, North America and North American ancestral lines determined by Amplified Fragment Length Polymorphism. Crop Sci 43:1858-1867.

Wange L, Guan R, Zhangxiong L, Chang R and Qui L (2006) Genetic diversity of Chinese cultivated soybean as revealed by SSR markers. Crop Sci 46:1032-1038.

Weir B (1990) Genetic Data Analysis: Methods for Desecrate Population Genetic Data. Sinauor Assoc, Sunderland, 376 pp.

Zabeau M and Vos P (1993) Selective restriction fragment amplification: A general method for DNA fingerprinting. European Patent Application number 92402629.7. Publication number $0534858 \mathrm{~A} 1$.

Associate Editor: Everaldo Gonçalves de Barros

License information: This is an open-access article distributed under the terms of the Creative Commons Attribution License, which permits unrestricted use, distribution, and reproduction in any medium, provided the original work is properly cited. 